\title{
Granulosa Cell Tumor Of The Ovary - An Incidental Finding During Caesarean Section - A Rare Case Report
}

\section{Roy J, ${ }^{1}$ Babu $\mathrm{AS}^{2}$}

\author{
${ }^{1}$ Department of Gynaecology and Obstretrics \\ ${ }^{2}$ Department of Pathology
}

College of Medicine and JNM Hospital, WBUHS

West Bengal, India

\section{Corresponding Author}

Jayeeta Roy

Department of Gynaecology and Obstretrics

College of Medicine and JNM Hospital, WBUHS

West Bengal, India

Email: roymitrajayeeta@gmail.com

\section{Citation}

Roy J, Babu AS. Granulosa Cell Tumor Of The Ovary - An Incidental Finding During Caesarean Section

- A Rare Case Report. Kathmandu Univ Med J 2014;45(1):60-63.

\begin{abstract}
Approximately one-fourth of the ovarian neoplasms and cysts are diagnosed incidentally during caesarean section. The possibility of borderline tumor or cancer should be considered although existence of ovarian malignancy in pregnancy is rare. We report a case of a rare solid malignant tumor of the ovary incidentally found during caesarean section. Intraoperatively, it was thought to be a variant of the common ovarian teratoma. Ovariectomy was done but histopathology revealed it to be granulosa cell tumor. The diagnosis changed the prognosis and future treatment plan drastically. Equipped with this knowledge physicians can be made aware of the existence of this little-known ovarian neoplasm along with its rare association with pregnancy. Also one can better manage, counsel and follow-up the patients after delivery, given the knowledge of the tumours' inevitable malignant potential and its high incidence of recurrence.
\end{abstract}

\section{KEY WORDS}

Follow-up, granulosa cell tumour, malignancy, ovariectomy, pregnancy, recurrence

\section{INTRODUCTION}

Approximately 24 percent of the ovarian tumors are incidentally discovered at caesarean section, inspite of the routine prenatal ultra sonogram. This underlines the importance of inculcating the habit of examining the ovaries at operation. ${ }^{1}$ Ovarian tumors associated with pregnancy are most commonly benign cystic teratomas, followed by serous cystadenomas. The incidence of malignant tumours is $4.5 \%$ in pregnancy. Whenever an ovarian tumor is found, the possibility of malignancy should always be borne in mind. ${ }^{1}$ GCT is a rare ovarian neoplasm accounting for less than five percent of all ovarian malignancies having an incidence of $0.5-1.5$ per 1,00,000 women per year. ${ }^{2-4}$ It constitutes $70 \%$ of all sex cord stromal tumor and is the most common(80\%) hormone-producing ovarian tumour. ${ }^{5}$ Though more than 50\% GCT occur in postmenopausal women, about one-third occur in premenopausal women. ${ }^{6}$

We report a case of malignant adult-type granulosa cell
tumour(GCT) found incidentally during caesarean section performed in the emergency operation theatre of our medical college hospital. So far, so very few such cases in pregnancy have been reported world-wide that not only its rarity adds to a diagnostic dilemma but also to the difficultly in the formulation of a definite plan of management. In addition to the above, to conceive a generalized follow-up protocol remains a tricky territory to tread in along with individualization of treatment for each patient.

\section{CASE REPORT}

A 23-year old primigravida with an uneventful antenatal period, presented at term with pre-mature rupture of membranes. She went into spontaneous labour. Emergency caesarean section had to be performed as her labor got prolonged and started showing early features of obstruction in the late first stage of labor. A baby boy 


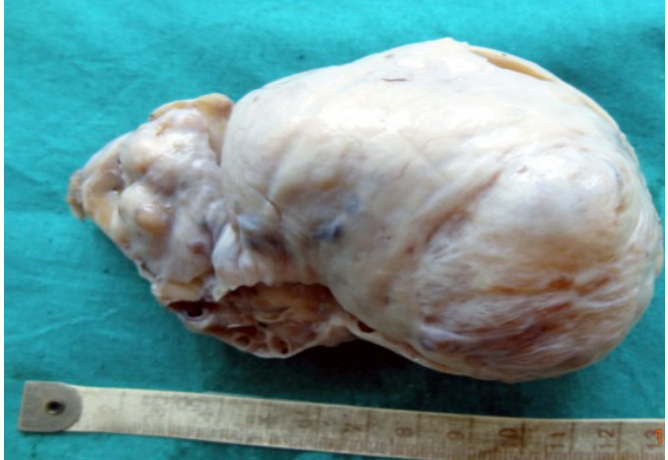

Figure 1. Gross of the ovary: enlarged ovary measuring $12 \mathrm{~cm} \times 10 \mathrm{~cm} \times 4 \mathrm{~cm}$ with smooth intact capsule.

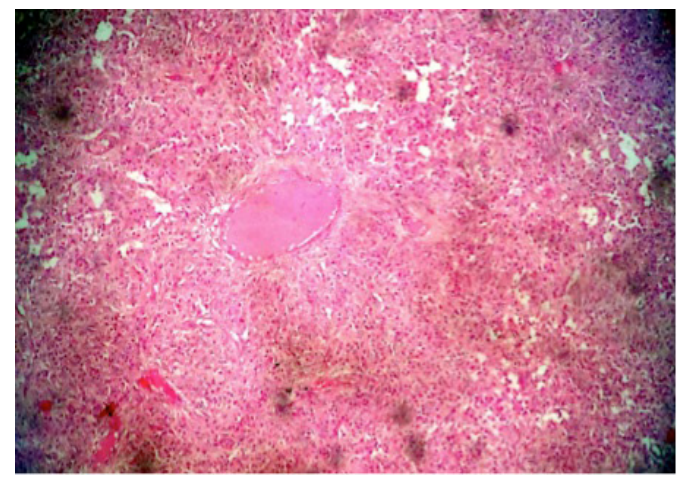

Figure 3. Microsection shows presence of CallExner body (H\&E stain, 100x magnification).

weighing $2.5 \mathrm{~kg}$ was delivered. Intraoperatively, proceeding further, a solid tumor was seen in the right ovary, which was thought to be a variant of the commonly occurring dermoid cyst of the ovary, measuring $10 \mathrm{~cm} \times 10 \mathrm{~cm} \times 5 \mathrm{~cm}$ approximately. Right sided ovariectomy was done and the specimen sent for histopathology. The rest of the operation and post-operative period went uneventfully and the patient was discharged on the fifth post-operative day. On receiving her histology report she was summoned to the post-natal clinic earlier than the usual six weeks, to receive specific followup instructions pertaining to the tumor.

The specimen of ovary that was received measured $12 \mathrm{~cm} \times 10 \mathrm{~cm} \times 4 \mathrm{~cm}$ with smooth intact capsule (Fig 1). Cross section of the ovary showed solid yellowish mass relpacing the whole ovarian stroma. There were multiple small cysts, few of them were filled with haemorrhage and blood clots (Fig 2).

Serial microsections from the ovary showed monotonous population of round to oval cells in diffuse sheets, in trabecular pattern and macrofollicular pattern separated by fibrous septa. Individual cells had pale nucleus with many showing nuclear grooving. Many leutinsed theca cells were also noted (Fig 3 and 4).

\section{DISCUSSION}

It is widely thought that GCTs develop as a result of stimulation of the granulosa cells, but the stimulus is

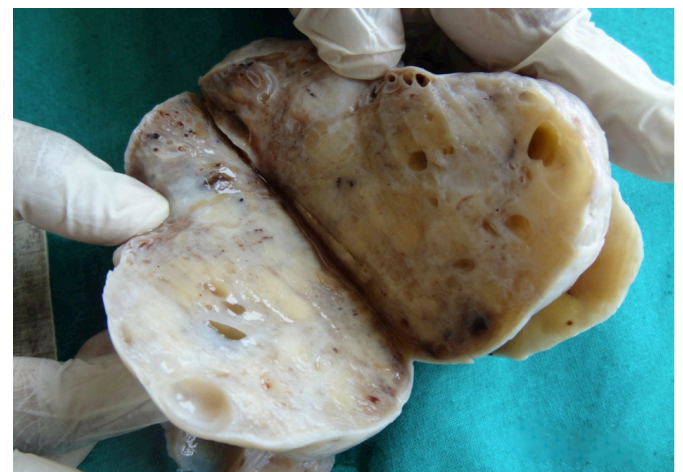

Figure 2. Cross-section of ovary : firm solid with multiple small cysts, few of them filled with blood clot.

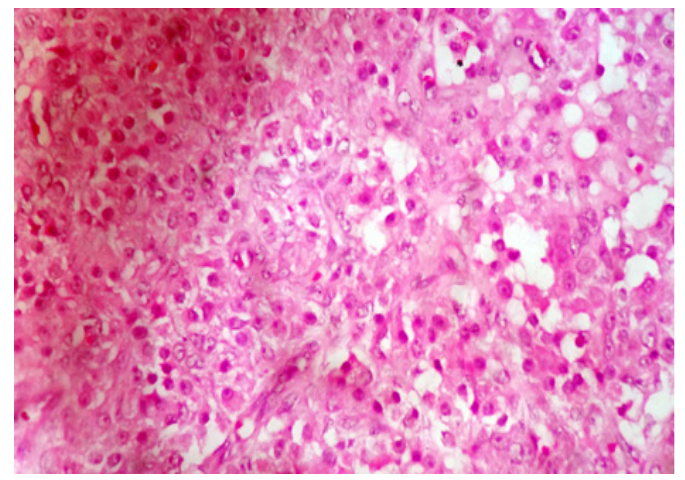

Figure 4. Microsection shows diffuse distribution of tumor cells showing nuclear grooving (400X magnification, H\&E stain).

unknown. $^{7}$

There are two types of GCT, the adult type and the juvenile type, the differences between types are merely histopathological. ${ }^{8}$

Though routine pelvic examination and ultrasonic scan aids diagnosis of $62.7 \%$ of ovarian tumours in early pregnancy, and the rest goes undetected as it happened in our case. ${ }^{1}$ In most patients, the presenting manifestation is usually abdominal pain or swelling. Some present with menstrual irregularities or amenorrhea. Postmenopausal women usually presents with uterine bleeding. ${ }^{6}$ Many others, like our patient, may present with features of obstructed labour, the ovarian tumour in the pelvis causing the obstruction.

All GCTs are malignant tumors having an indolent course. These uncommon neoplasms usually involve unilateral ovary and are characterized by late recurrence and high survival rates. ${ }^{9}$ The propensity towards recurrence of the disease often happens after five years and in up to $25 \%$ of patients. ${ }^{10,11}$ Recurrent GCT has been known to present after 37 years after initial diagnosis, i.e. when the tumour is nearly 'forgotten' by the patient. ${ }^{10}$ Hence the importance for extended follow-up needed for these patients cannot be overemphasized. ${ }^{9}$

Granulosa cell proliferations simulate small ovarian neoplasm and have been commonly encountered as incidental findings in pregnant women. ${ }^{12}$ The FSH- 
like properties of hCG in pregnancy causes the altered hormonal milieu that leads to these unusual non-neoplastic proliferations. The granulosa cells in the proliferations typically contain scanty cytoplasm and grooved nuclei, resembling the cells of the adult-type GCT and may be arranged in such a way mimicking similar patterns in clinically evident small GCT. But, these proliferations in pregnant women are usually multiple and lie within atretic follicles that are typically enveloped by a thick layer of lutenized theca cells. The microscopic size, multifocality and confinement to atretic follicles distinguish them from GCT and prevents from making errors in diagnosis. ${ }^{13}$

Total abdominal hysterectomy and bilateral salpingooophorectomy is the primary treatment that is associated with improved survival and longer relapse-free interval. The estimated survival for stage I GCT is $93 \%$ at five years, $84 \%$ at 10 years, and $62 \%$ at 20 years. ${ }^{14}$ The optimal treatment of GCT in younger women in whom the preservation of fertility is desired is unilateral salpingo-oophorectomy (justifiable if spread beyond the ovary is not demonstrable and examination of the contralateral ovary shows no suggestion of involvement; stage la GCT) is feasible option as opposed to total hysterectomy with bilateral salphingooophorectomy in menopausal women. ${ }^{5}$ No postoperative treatment is required for patients with early stage disease (stage I and II) as they have a very good prognosis with five year disease-free-interval and overall-survival of $89 \%$ and $99 \%$ respectively. ${ }^{2}$ However, patients with stage Ic disease associated with poor prognostic factors like large tumor size or high mitotic index and stage II, have a higher chance of relapse, and may benefit with postoperative treatment but role of chemotherapy is still debatable. ${ }^{2}$

Of the various features that are evaluated for prognostic significance, a low stage of the tumor correlates best with survival. Almost $90 \%$ of the GCT are stage-I, and have a higher chance $(86 \%)$ of relative survival at 10 years than the higher-stage tumours (49\%). ${ }^{15}$ Studies have shown that the size of GCT also has been related to their prognosis, i.e. tumours having size $<5 \mathrm{~cm}$ had $100 \% 10$-year survival rate compared to $63 \%$ and $34 \%$ with those having tumours $5-15 \mathrm{~cm}$ and $>15 \mathrm{~cm}$, respectively. ${ }^{5}$ Nuclear atypicality is considered the most reliable prognostic index in cases of stage-I tumours; for higher-stage tumours, nuclear atypicality and mitotic rate are of similar significance. ${ }^{15}$ Though tumours with many mitotic figures are associated with a worse prognosis than those with few, it has been observed that tumours with high mitotic rates are also at a higher stage than those with low mitotic rates, and the differences are unlikely to have a statistically significant effect on the prognosis of stage-I tumours. ${ }^{5}$ However, no definite correlation has been established between histologic pattern, the degrees of nuclear atypia and the mitotic activity and the prognostic importance of granulosa cell tumour. ${ }^{5}$

In our case, the mitotic count was less than 1/10 HPF(very low mitotic count), nuclear grade was low grade, and the capsule was totally intact(stage-I). The typical grooved, pale nuclei was seen on microscopy. Since there is subjective variation with regard to nuclear atypicality and prognosis, it is difficult to predict early recurrences and impossible to predict late recurrences using these clinical and pathologic parameters. ${ }^{5,11}$ Tumor stage and, to a lesser extent, tumor size are the onlyclinical parameters of prognosticimportance in adult granulosa cell tumors. Cellular atypia and, to lesser extents, mitotic rate and the absence of Call-Exner bodies are the only significant pathologic prognosticators. The only clinical factor unequivocally related to recurrence is stage, but other factors such as patient age, tumor size, and extent of surgery have also been noted to be of prognostic importance. Histologic prognostic factors include atypia and mitosis, but not tumor patterns. ${ }^{11}$

Nowadays, early detection of GCT might be possible due to the availability of specific and ultrasensitive assays both for inhibin $\mathrm{B}$ and $\mathrm{AMH}$. Antimüllerian hormone is a more specific serum parameter than inhibin, because inhibin may also increase in some (mucinous) epithelial ovarian tumors. These peptide hormones inhibin B and antimüllerian hormone (AMH), both produced by the granulosa cells, are potential candidates for diagnosis of GCTs and seem to be reliable markers during follow-up for early detection of residual or recurrent disease. Elevated concentrations of these hormones predict relapse earlier than clinical symptoms, which leads to less morbidity of the patients. Currently, there is no evidence-based preference for inhibin $\mathrm{B}$ or $\mathrm{AMH}$ as tumor marker. ${ }^{16}$

Recurring adult-type granulosa cell tumors of the ovary are usually treated by surgical resection, chemotherapy or radiation, or a combination of the treatment modalities.

However, the results of such treatment are disappointing. Recurrent ovarian granulosa cell tumors may also be treated with an aromatase inhibitor, with promising results. ${ }^{17}$

When a pregnant woman is diagnosed with cancer, the evaluation and decision sometime involves competing maternal and fetal risks and benefits. There are recommendations that attempt to balance these risks and benefits to offer appropriate treatment to the mother without placing the fetus at serious risk. ${ }^{18}$ Consultation with specific interdisciplinary specialists in maternal-fetal medicine, gynecologic oncology and pediatrics, as well as imaging and pathology, are needed for proper management and followup of such cases. ${ }^{18}$ The optimum follow-up strategy of GCT patients remains controversial. Ideally, in this case, during each follow-up visit, a history should be obtained and pelvic examination should be performed. In a case like ours where GCT had been incidentally detected, a serum inhibin level should be done post-operatively and it is to be followed up subsequently in the later visits till its value is found raised. This follow-up should occur at 2to 3-month intervals for the first 2 years, then every 4-6 months for the next 3 years, then yearly thereafter for patients such as ours with early stage adult GCT, and who 
would therefore not need chemotherapy because of her being in the early stage of tumour detection. ${ }^{19}$ In case there is any evidence of recurrence during follow-up, and keeping in mind that most recurrences are confined to the abdomen and pelvis, an abdominopelvic CT scan should be performed to look for recurrent tumors. Other imaging studies may be ordered as dictated by physical examination findings. ${ }^{19}$ Long-term follow-up is required in all patients with GCTs because at least $50 \%$ of recurrences are found more than 5 years after initial treatment. The multidisciplinary team treated our patient on her postnatal visit and elaborated on the nature of her follow-up as mentioned above. She

\section{REFERENCES}

1. el-Yahia AR, Rahman J, Rahman MS, al-Suleiman SA. Ovarian tumours in pregnancy. Aust N Z J Obstet Gynaecol. 1991 Nov;31(4):327-30.

2. Kottarathil VD, Antony MA, Nair IR, Pavithran K. Recent Advances in Granulosa Cell Tumor Ovary: A Review. Indian Journal of Surgical Oncology. 2013;4(1):37-47.

3. Malmström H, Högberg $T$, Risberg B, Simonsen E. Granulosa cell tumors of the ovary: prognostic factors and outcome. Gynecol Oncol. 1994 Jan;52(1):50-5.

4. Ohel G, Kaneti H, Schenker JG. Granulosa cell tumors in Israel: a study of 172 cases. Gynecol Oncol. 1983 Apr;15(2):278-86.

5. Young RH. Sex cord - stromal, steroid cell and other ovarian tumors with endocrine, paraendocrine, and paraneoplastic manifestations. In Blaustein's Pathology of the Female Genital Tract (6th edn), Kurman RJ, Ellenson LH, Ronnett BM (ed.). Springer Science+Business Media, LLC 2011: New York, Dodrecht, Heidelberg, London; 2011. pg. 786800 .

6. Young RH, Dickersin GR, Scully RE. Juvenile granulosa cell tumor of the ovary: a clinicopathological analysis of 125 cases. Am J Surg Pathol. 1984 Aug;8(8):575-96.

7. Van Holsbeke C, Domali E, Holland TK, Achten R, Testa AC, Valentin $L$ et.al. Imaging of gynecological disease (3): clinical and ultrasound characteristics of granulosa cell tumors of the ovary. Ultrasound Obstet Gynecol. 2008 Apr;31(4):450-6.

8. Zaloudek C. The ovary. In Pathology in Gynecology and Obstetrics (4th edn), Gompel C, Silverberg SG (eds). Lippincott: Philadelphia, PA, 1994; 313-413.

9. Hines JF, Khalifa MA, Moore JL, Fine KP, Lage JM, Barnes WA. Recurrent granulosa cell tumor of the ovary 37 years after initial diagnosis: a case report and review of the literature. Gynecol Oncol. 1996 Mar;60(3):484-8. was counseled regarding the nature of the tumour, and a follow-up treatment plan individualized for her.

\section{CONCLUSION}

Granulosa cell tumor is a tumor of unquestionable malignant potential and has a tendency for late relapses. Fertility preserving surgery may be appropriate in young patients suffering from this malignancy. Adequate counseling followed by long-time follow-up with specialists in the multidisciplinary team is recommended to ensure thorough recovery and proper care.

10. Chen YC, Chang LC, Soong RS. A late recurring and easily forgotten tumor: ovarian granulosa cell tumor. World J Surg Oncol. 2012 May 16;10:85.

11. Miller BE, Barron BA, Wan JY, Delmore JE, Silva EG, Gershenson DM. Prognostic Factors in Adult Granulosa Cell Tumor of the Ovary. Cancer. 1997 May 15;79(10):1951-5.

12. Clement PB, Young RH, Scully RE. Ovarian granulosa cell proliferations of pregnancy: a report of nine cases. Hum Pathol. 1988 Jun;19(6):65762.

13. Irving JA, Clement PB. Neoplastic lesions of the ovary. In Blaustein's Pathology of the Female Genital Tract (6th edn), Kurman RJ, Ellenson LH, Ronnett BM (ed.). Springer Science+Business Media, LLC 2011. New York, Dodrecht: Heidelberg, London; 2011pg. 608-609.

14. Lauszus FF, Petersen AC, Greisen J, Jakobsen A. Granulosa Cell Tumor of the Ovary: A Population-Based Study of 37 Women with Stage I Disease. Gynecologic Oncology. Gynecol Oncol. 2001 Jun;81(3):45660.

15. Bjorkholm E, Silfversward C. Prognostic factors in granulosa cell tumors. Gynecol Oncol. 1981 Jun;11(3):261-74.

16. Geerts I, Vergote I, Neven P, Billen J. The Role of Inhibins B and Antimullerian Hormone for Diagnosis and Follow-up of Granulosa Cell Tumors. Int J Gynecol Cancer. 2009 Jul;19(5):847-55.

17. Korach J, Perri T, Beiner M, Davidzon T, Fridman E, Ben-Baruch G. Promising Effect of Aromatase Inhibitors on Recurrent Granulosa Cell Tumors. Int J Gynecol Cancer. 2009 Jul;19(5):830-3.

18. Marret $H$, Lhommé $C$, Lecuru $F$, Canis $M$, Lévèque J, Golfier $F$ et.al. Guidelines for the management of ovarian cancer during pregnancy. Eur J Obstet Gynecol Reprod Biol. 2010 Mar;149(1):18-21.

19. Colombo N, Parma G, Zanagnolo V, Insinga A. Management of ovarian stromal cell tumours. J Clin Oncol. 2007; 25: 2944-51. 